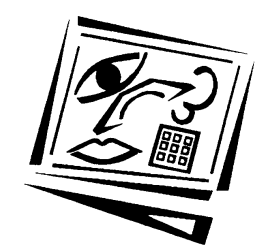

\title{
Using computer-based instruction to improve Indigenous early literacy in Northern Australia: A quasi-experimental study
}

\author{
Jennifer Wolgemuth \\ Colorado State University \\ Robert Savage \\ McGill University \\ Janet Helmer, Tess Lea, Helen Harper, Kalotina Chalkiti, Christine Bottrell \\ Charles Darwin University \\ Phil Abrami \\ Concordia University
}

\begin{abstract}
The effectiveness of a web-based reading support tool, ABRACADABRA, to improve the literacy outcomes of Indigenous and non-Indigenous students was evaluated over one semester in several Northern Territory primary schools in 2009. ABRACADABRA is intended as a support for teachers in the early years of schooling, giving them a friendly, game and evidence-based tool to reinforce their literacy instruction. The classroom implementation of ABRACADABRA by briefly trained and intensively supported teachers was evaluated using a quasi-experimental pretest, post-test control group design with 118 children in the intervention and 48 in the control. Children received either a minimum of 20 hours of technology-based intervention or regular classroom teaching. Results revealed both Indigenous and non-Indigenous students who received ABRACADABRA instruction had significantly higher phonological awareness scores than their control group peers. The effect size for this difference was large $\left(\eta^{2}=.14\right)$. This finding remained when controlling for student attendance and the quality of general non-technology-based literacy instruction. Limitations of the study and implications for effective practice in remote and regional contexts are discussed.
\end{abstract}

\section{Background}

The 1998 Australian Government publication The National Report on Schooling in Australia challenged Australian educators to ensure that "every child leaving primary school should be numerate and able to read, write and spell at an appropriate level" (Department of Employment, Education, Training and Youth Affairs, 1998, p. 9).

The National Report also ushered in an era of increased emphasis on assessment and evaluation in Australia, leading to the introduction of assessment at Years 3, 5, 7 and 9 to measure students for the reporting of student and school achievement. One issue brought to the fore by the national testing system is the significant 'gap' in the academic achievement between Indigenous and non-Indigenous students, with Indigenous students lagging far behind their non-Indigenous counterparts (Masters \& Forster, 1997; Ladwig \& Sarra, 2009, p. 14). For example, in the Northern Territory 
(NT), which has the greatest proportion of Indigenous students (45\% of students in the NT are Indigenous), only $40 \%$ of Indigenous students achieved minimum benchmarks in reading by Grade 3, compared to $90 \%$ of non-Indigenous students in 2009 (ACARA, 2010). Wise, da Silva, Webster and Sanson (2005) recommend interventions in the early years of schooling to remediate the literacy gap between Indigenous and nonIndigenous students. Similarly, Leigh \& Gong (2008) provide evidence that the gap widens during school years, which suggests interventions targeted at Indigenous children in early schooling could well have a significant impact.

Reasons for poor literacy outcomes among Indigenous students are complex, and it has been convincingly argued that they are part of a colonial, historical, social and cultural dynamic that resists straightforward delineation (Bourke, Rigby \& Burden, 2000; Gray \& Hunter, 2000; Louden, et al., 2005). Alongside these important distal factors, two proximal factors that may affect these outcomes, positively or adversely, are attendance and teacher quality. Australian Bureau of Statistics data show reasons for absences of Indigenous students from school include cultural events, illness, sorry business (funerals) and community flooding (2009). However, school attendance may also be a response to quality and continuity of teaching. In 2009 over 550 of the 2133 (26\%) teachers in the NT left their positions and teacher turnover is known to be higher in remote communities, in some instances leaving remote schools sorely understaffed (NT DET, 2009).

Whatever the reasons for poor overall literacy performance, Indigenous students' results point to the need for early, intensive and evidence-based reading interventions. This paper investigates the impact of an early literacy intervention, ABRACADABRA (CSLP, 2009), that targets children identified as struggling readers, on Indigenous student literacy in Australia's Northern Territory (NT). The term 'literacy' is used here in the sense elaborated by the Australian National Curriculum Board (ACARA, 2009, p.6), as referring to 'a flexible, sustainable mastery of a set of capabilities in the use and production of traditional texts and new communications technologies using spoken language, print and multimedia.' The ability to read print fluently is one aspect of literacy. A strong consensus in research evidence suggests that among other abilities, fluent word reading underpins this capacity for reading fluency and that this in turn is underpinned by foundational alphabetic skills early in reading acquisition (e.g. Byrne, 1998; Savage et al., 2007).

\section{The NT context}

\section{Literacy instruction quality}

There is little doubt that some teachers are more effective than others (DarlingHammond \& Young, 2002) and a number of factors internationally and in Australia have contributed to a current shortage of teachers with appropriate qualifications, skills and experience across a number of discipline and subject areas. Staffing issues such as frequent turnover, matching experience to teaching position and attracting teachers who are suitably qualified, are becoming increasingly significant in Australian education. These issues are exacerbated in the NT and other remote areas of the country (Lyons, Cooksey, Panizzon, Parnell \& Pegg, 2006) where employing teachers who are appropriately skilled in teaching early years literacy, familiar with early childhood teaching and learning environments, and experienced in teaching in Indigenous contexts presents a greater challenge. Student achievement, especially for 
Indigenous students, is likely to suffer as research shows a student's teacher has a greater impact on his/her academic achievement than other factors such as class size and composition (Darling-Hammond \& Young, 2002; Sanders \& Rivers, 1996).

\section{Attendance}

Indigenous students in the NT attend school on average 20\% less than their nonIndigenous counterparts (DET, 2011). McGarrigle and Nelson (2006) state one in eight Indigenous Australians between 5 and 9 years of age never attend school or are frequently absent from school. Reasons often cited for Indigenous student absenteeism include a perceived lack of relevance of schooling on the part of Indigenous students, the inability of teachers to relate to their Indigenous students, and lack of parental support in getting children to school (Bourke, Rigby \& Burden, 2000; Gray \& Beresford, 2008). In particular, it has been noted that absenteeism may serve as "a protective mechanism which allows students to avoid those aspects of school they find undesirable, frustrating or a cause of shame" (Bourke, Rigby \& Burden 2000, p. 7).

Punitive attempts to improve attendance either through local 'no school, no pool' policies (Ah Kit, 2004) or by linking welfare payments to student attendance (Behrendt \& McCausland, 2008) have had little sustained impact on improving student attendance. Increased school attendance in remote communities appears to be associated with more positive measures such as providing breakfast, creating a welcoming school climate and offering programs in which students are engaged (Batten and Russell, 1995); however, much of the evidence for improved attendance is anecdotal. A number of studies show that poor attendance at school has an adverse effect on student academic achievement generally (Dunn, Cadane \& Garrow, 2003; Gray \& Partington, 2003; Mellor \& Corrigan, 2004), and on the achievement of Indigenous students in particular (Ehrich, et al., 2010; Frigo, et al., 2004). In turn, poor achievement may compound the reasons for poor attendance.

In the NT, attendance and quality of instruction are major factors that impact on student achievement and must be considered when designing and implementing effective programs for Indigenous students. An easily delivered, self-paced literacy program that supports teachers to provide direct early literacy instruction may help counter the effects of frequent student absences and inadequate preparation to teach in the early years.

\section{ABRACADABRA}

ABRACADABRA is an interactive computer tool, designed to assist teachers to improve early childhood students' foundational literacy skills. It is available entirely free online at http://www.abralite.concordia.ca/. Drawing on best practice recommendations from the United States' National Reading Panel (National Institution of Child Health and Development, 2000), ABRACADABRA was originally developed in 2002 (development is ongoing) by a team of literacy and classroom technology experts at the Centre for the Study of Learning and Performance (CSLP) in Montreal, Canada, to improve the literacy of students at risk of school failure (for a description of the development of ABRACADABRA see Hipps, Abrami \& Savage, 2005; Abrami et al., 2010). ABRACADABRA activities are organised into alphabetics, fluency, comprehension and writing categories (the foundations of literacy acquisition), so that teachers can target specific skills for instruction or guide students 
to progress from basic sound and letter identification to complex tasks such as spelling, and personal responses to stories.

ABRACADABRA has been shown to enhance student literacy in Canada with a wide range of learners. Since 2004, several randomised controlled trials (RCTs) and quasiexperimental studies have been conducted in Canadian classrooms to measure the impact of ABRACADABRA on the literacy development of kindergarten (transition) and grade 1 students. The Canadian RCT data to date has shown that ABRACADABRA aids typical students in Grade 1 (Savage, Abrami, Hipps \& Deault, 2009) as well as children with poor attention (Deault, Savage \& Abrami, 2009) and low socio-economic pre-reading students in transition level classrooms (Comaskey, Savage \& Abrami, 2009). An RCT comparing two different ABRACADABRA treatments (ABRACADABRA with a focus on synthetic phonics and ABRACADABRA with a focus on analytic phonics) to typical instruction revealed significant advantages for ABRACADABRA students on key literacy skills of letter-sound knowledge, phonological blending, listening comprehension and reading comprehension (Savage, et al., 2009; Savage, et al., 2008). Results of an RCT conducted in kindergarten, first and second grade classrooms in Canada showed ABRACADABRA students significantly outperform non-ABRACADABRA students on measures of sight word reading and phonological blending (Savage, et al., 2008).

However, there have been very few rigorously designed studies in Australia investigating the use of computer software to support literacy learning for students in general (Brooks, Miles, Torgerson \& Torgerson, 2006); and within the Indigenous domain, there is an extreme lack of information. What we do know about the effectiveness of computer-based literacy instruction with struggling readers suggests that these programs provide teachers with explicit strategies for teaching literacy, making them potentially useful in remediating literacy gaps (Fish et al., 2008; Garcia \& Arias, 2000; Phillips, Clancy-Menchetti \& Lonigan, 2008). Computer-based instruction may equalise learning opportunities by increasing the opportunities for all students to participate in literacy activities (Hitchcock \& Noonan, 2000; Hutinger, Bell, Daytner \& Johanson, 2006). Further to participation, early readers can achieve greater independence in their literacy development because of the motivational features of technology (Leloup \& Ponterio, 2003). Also, computer-based programs are believed to be well suited for supplementary instruction to reading and, in turn, offer more intensive practice (Magnan \& Ecalle, 2006).

As a flexible, evidence-based literacy intervention with a history of positive effects, ABRACADABRA was selected as a promising platform for rigorous research on improving Indigenous literacy in the NT. Given the limited capacity to conduct systematic research in the NT, especially within the remote schools, designing a program of research around an established literacy instruction tool enabled our research to build teachers' skills whilst being confident the intervention is unlikely to do harm.

\section{Purpose and research questions}

The purpose of this study was to determine whether ABRACADABRA improves Indigenous student literacy in the NT (as compared to non-Indigenous and Indigenous control group students) and whether the quality of literacy instruction and student attendance would impact ABRACADABRA's effectiveness (for an analysis of additional research questions, see the full end-of year report [Wolgemuth et al., 2009]). 
The study was guided by the following research questions:

RQ1. Is there a difference in post-test literacy scores between Indigenous and non-Indigenous students who do and do not receive ABRACADABRA instruction when controlling for pretest scores?

RQ2. Do the differences in research question 1 remain when students' post-test literacy scores are adjusted for by attendance and literacy instruction quality?

\section{Methods}

A quasi-experimental pretest-post-test control group design was used to assess the impact of ABRACADABRA on student literacy. Structured observations assessed the quality of literacy instruction.

\section{Instruments and data collection}

Student literacy was assessed using the Group Reading Assessment and Diagnostic Evaluation (GRADE) level K (Williams, 2001) and the Performance Indicators in Primary Schools Baseline Assessment (PIPS-BLA) instruments (Tymms, 2002). University researchers and volunteers from the corporate sponsor (the Telstra Foundation) attended a half-day training on administering the GRADE and PIPS-BLA instruments. Student testing was conducted two to five days prior to and after the ABRACADABRA intervention. All assessments were conducted one-on-one in private or semi-private rooms (resource rooms or libraries) and took approximately 45 minutes per student (25 minutes for the GRADE, 20 minutes for the PIPS-BLA). Administering the GRADE and PIPS-BLA one-on-one enabled testers to assist students in attending to the assessment and ensure students with hearing impairments correctly heard the questions and response options (Helmer et al., under review).

Prior to pretesting, students were randomly assigned to one of two parallel forms of the GRADE K (A or B) and to whether they received the GRADE K or the PIPS-BLA assessment first. Students who received the GRADE K A at pretest were post-tested using the GRADE K B and vice versa. Students who received the GRADE K first at pretest received the PIPS-BLA first at post-test and vice versa.

Literacy instruction quality was assessed during bi-weekly site visits by university researchers who used a revised version of the Classroom Literacy Observation Survey instrument (Louden \& Rohl, 2003) to evaluate control and ABRACADABRA teachers' literacy lessons. A total of 92 observations were conducted for an average of 6 observations per teacher.

GRADE K

Four GRADE K subscales (phonological awareness, early literacy skills, phonemegrapheme correspondence and word reading) were used. The GRADE has been shown to have strong internal consistency (.95-.99), high alternate form reliability (.81-.94), and high test-retest reliability (.80) (Williams, 2001).

PIPS-BLA

The PIPS-BLA is a computer-based literacy and numeracy assessment developed by the Curriculum Evaluation Management (CEM) Centre at Durham University in 
England and consists of three measures: Reading, Maths and Phonics. Test-retest reliability for the UK version of the PIPS-BLA ranged from .91 to .98 and predictive validity for reading and maths was .70 and .65, respectively (Tymms, 2002). Studies have shown the four scales to be internally reliable with Cronbach's alphas of 0.95, $0.93,0.86$ and 0.86 for Reading, Mathematics, Vocabulary and Phonological Awareness, respectively (Merrell \& Tymms, 2007).

In Australia, studies have examined the reliability and validity of the PIPS-BLA when used with Indigenous students. Godfrey and Galloway (2004) administered the PIPSBLA to 191 Indigenous students from government primary, Catholic primary and community primary schools and found Cronbach's alpha was .98 and split-half reliability was .98 , leading them to recommend the PIPS-BLA to "...teachers as a reliable instrument to use with Indigenous students" (p. 154).

Literacy teaching practices observation instrument and teacher perceptions

The Literacy Teaching Practices Observation instrument was developed based on the Classroom Literacy Observation Survey (Louden \& Rohl, 2003). The CLOS is a 33 item teacher literacy practice observation instrument divided into 6 key areas: Participation, Knowledge, Orchestration, Support, Differentiation and Respect (Louden \& Rohl, 2003; Louden, et al., 2005). All items from the CLOS were retained in the Literacy Teaching Practices Observation instrument, but the scale was modified from a checklist of present or absent behaviours to a rating scale from 1 to 5 with 1 being 'Strongly Disagree' and 5 being 'Strongly Agree.' This change was made to better assess the quality of literacy practices, rather than their presence or absence. Two university researchers observed 5 lessons together and their inter-rater reliability was .98 for the overall average test score (.90 for Knowledge, .99 for Participation, .90 for Orchestration, .99 for Support, .97 for Differentiation and .97 for Respect). Cronbach's alpha was .98. Teachers' average total score on the literacy teaching practices observation instrument was used as the literacy instruction quality covariate.

Teachers' perceptions of ABRACADABRA were gathered during two telephone-based focus groups facilitated by the university researchers at the mid-point and end of the ABRACADABRA implementation. These focus groups were transcribed, analysed for common themes and used to inform the interpretation of our findings.

\section{ABRACADABRA intervention}

Implementation of ABRACADABRA began after a full-day teacher training during week 3 of Term 1, Semester 1 and continued through to the end of Term 2, Semester 1 2009 for a total of 16 weeks. The training was delivered by two university researchers who were both former early childhood teachers and had expertise in early literacy instruction. The teacher training emphasised the development of complete ABRACADABRA lesson plans (with an introduction, demonstration, group/ individual computer time, and a review) and using ABRACADABRA for phonological awareness instruction. Teachers were asked to use ABRACADABRA as part of their literacy instruction for a minimum of 30 minutes per day, 4 days per week. ABRACADABRA teachers were supported through bi-weekly onsite visits during which the university researchers helped teachers to design lessons, suggested areas for improvement and answered questions about ABRACADABRA. Teachers reported that the level of support benefitted their delivery of ABRACADABRA and strengthened their literacy teaching (Helmer et al., 2011). 


\section{ABRACADABRA classes}

ABRACADABRA takes into account literacy theory and a socio-constructivist approach (Bodrova \& Leong, 2007; Palincsar, 2003) for learning with activities that include built in scaffolding and support. Children who use ABRACADABRA are actively engaged in activities designed to demand a higher level of literacy knowledge as they progress. Whether working in a group or individually, children are given opportunities to discuss, reflect and question their learning, allowing them to further assimilate the literacy skills being reinforced while using ABRACADABRA. In ideal ABRACADABRA instruction, this computer work is often followed up with multimodal activities such as art, science activities or seatwork giving the students the opportunity to apply the knowledge learnt while using the computer.

Throughout the study, researchers observed how ABRACADABRA's multiple levels, activities and entry points allowed teachers to augment lessons for varying learning needs and school resources. At one remote community school, teachers used a learning centre approach that involved four children on laptops whilst others worked on other complementary literacy activities. At another very remote school two teachers used an activity centre approach one day a week with 4 children using ABRACADABRA on the interactive white board and all the children rotating between the learning centres approximately every 15 minutes. At the provincial city schools, teachers used an interactive white board to introduce lessons and then most students moved to a larger computer lab where children could practise activities on their own computers, whilst other students who needed more support received guided practice on the interactive whiteboard with the teacher or teacher assistant. Early in the intervention teachers found that students required a high level of support as they worked individually or in pairs on the computer. As they became more confident with the navigation of the program, most children were able to take greater responsibility for their learning, needing only minimal teacher support.

\section{Control classes}

The control teachers delivered the regular literacy program in place at their schools. In the NT it is mandated that schools spend at least two hours on literacy instruction per day. The literacy program used by 3 control teachers was Accelerated Literacy, an approach to teaching literacy that uses 'literate texts' to help teach children read at an age-appropriate level (Gray \& Cowey, 2004). Another teacher used First Steps, a balanced literacy program that uses a "Gradual Release of Responsibility Model, improving fluency, developing phonological awareness, teaching graphophonics, developing comprehension and building vocabulary and text form knowledge" (Annadale, et al., 2004, p. ). The final teacher delivered an eclectic literacy curriculum using ESL strategies to underpin her teaching.

\section{Intervention and control groups}

The selection of schools to participate was purposive. An initial list of 20 schools to target for recruitment was generated with the assistance of the NT Department of Education and Training. Recruiters contacted the school principals by telephone and email, aiming to recruit at least one school from each of three Australian Bureau of Statistics geographic classifications in the NT (provincial, remote and very remote). A total of six NT schools volunteered to participate in the study. Schools were asked to 
nominate at least two early childhood classrooms (kindergarten to year 2) to participate, one that would serve as the intervention and one the control. Despite guarantees that control teachers would be trained to use ABRACADABRA after the study was completed, most schools nominated more than two classes and requested the additional classes be allocated to the intervention. One school only nominated one class whose teacher wanted to use ABRACADABRA. We elected to honour the schools' requests in order to foster buy-in and good will, despite the limitations of an unequal balance in the design. As the ABRACADABRA research was in its second year of a three year project and had met with some resistance during the first year feasibility study (Helmer et al., under review), maintaining positive relationships with the schools was seen as essential to ensuring the quality of the current study and recruiting schools to participate in the randomised controlled trial planned for year three.

A total of fourteen early childhood classrooms from 2 provincial, 2 remote, and 2 very remote schools volunteered to participate in the study. Of the 14 classrooms, 5 were controls and 9 were interventions. The 14 classes were taught by 16 teachers whose years of teaching experience ranged from 2 to $37(M=15.4, \mathrm{SD}=10.5)$ and who had been early childhood teachers between 1 and 15 years $(M=7.0, \mathrm{SD}=6.0)$. Two classes were cotaught by two teachers. The teachers were mostly female $(93 \%)$.

\section{Students}

At the beginning of the 2009 school year there were 289 students enrolled in the 14 classes. Only the 242 students who were pretested were considered to be part of the study. Of these students, 185 were post-tested yielding an overall attrition rate of $25 \%$. This attrition rate reflects the typical high levels of absenteeism and student mobility amongst Indigenous students in the NT (Dunn, 2009a; Dunn 2009b). Additionally, all 19 students from one control class were excluded from the analysis due to contamination. School visits revealed the teacher of this control class used ABRACADABRA on at least 4 occasions and student interviews revealed a level of familiarity with the ABRACADABRA program similar to that of intervention group students. The details of the sample for the GRADE assessment are depicted in the flow diagram (Figure 1) following CONSORT criteria for experimental studies (Altman et al., 2001; Moher, Schulz \& Altman, 2001).

The proportion of Indigenous students was $56.8 \%$ in the intervention group and $60.4 \%$ in the control group (see Table 1). There was no difference between intervention and control groups in their Indigenous student compositions $\left(\chi^{2}=.18, \mathrm{p}=.67\right)$. Average attendance rates, calculated by dividing the number of school days attended by the total number of school days in Semester 1, ranged from 80\% (Indigenous students in the intervention group) to $94 \%$ (non-Indigenous students in the control group). Average literacy instruction quality scores, on a scale from 1 to 5 with 1 being 'low' and 5 being 'high,' ranged from 2.23 (Indigenous students in the control group) to 2.74 (Indigenous students in the intervention group). Students in the control group had significantly higher attendance $(X=.90, \mathrm{SD}=.09)$ than students in the intervention group $(X=.86, \mathrm{SD}=.14)\left(t_{159}=2.09, p=.04\right)$. Permitted to select which classes would serve as the intervention and controls, the schools may have tended to choose classes for intervention viewed as in need of remedial instruction. These classes would be more likely to have lower student attendance and pretest literacy scores (although analyses revealed the pretest differences between intervention and control classes were not significant [see Table 2 in Results]). Students in the intervention group also received 


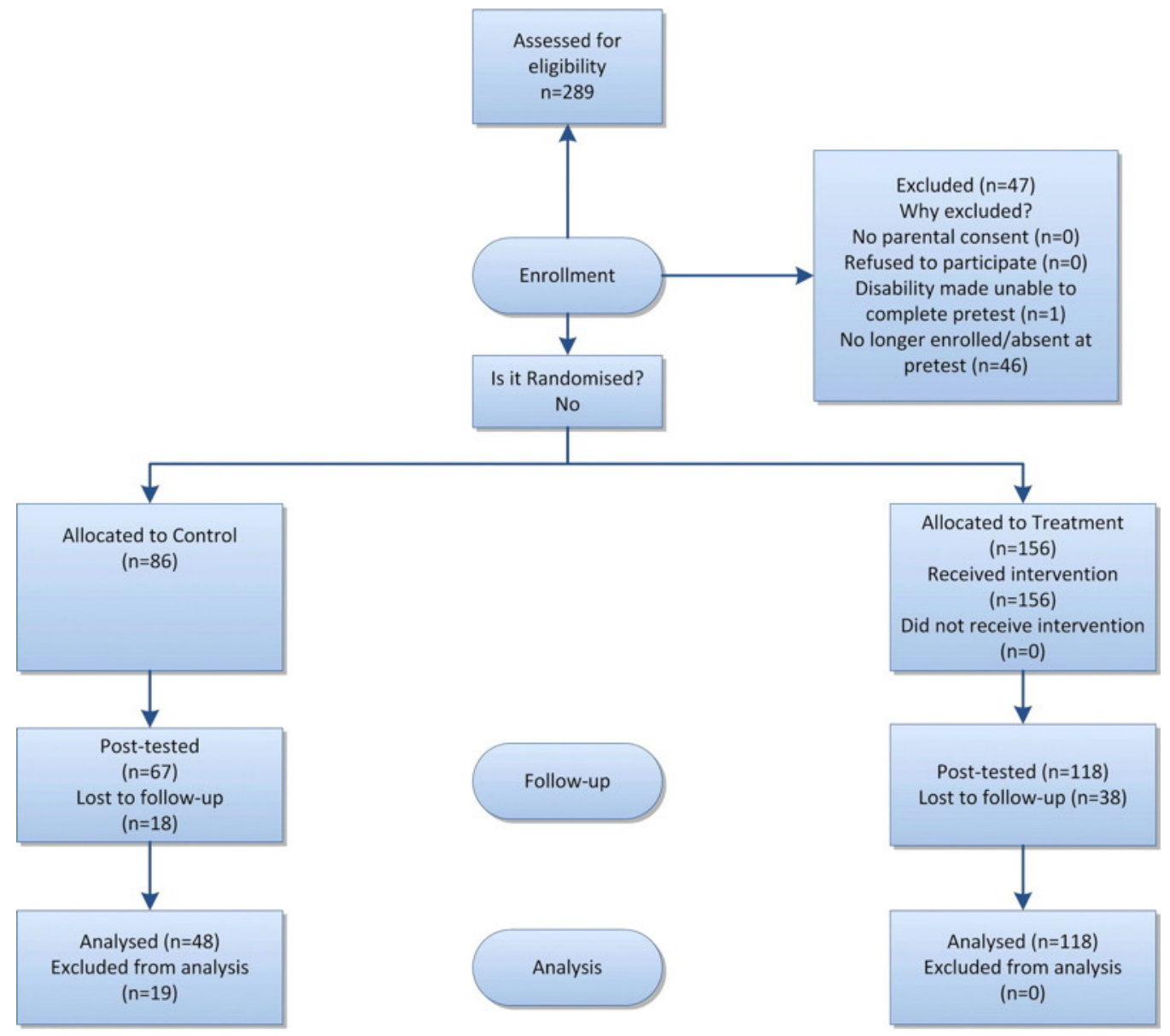

Figure 1: Participant flowchart for the 2009 ABRACADABRA study

significantly better literacy instruction $(X=2.54, \mathrm{SD}=.70)$ than students in the control group $(X=2.30, \mathrm{SD}=.25)\left(t_{164}=3.29, p=.001\right)$. This finding is likely related to the extra training and support in literacy instruction the intervention teachers received as a result of participating in the study.

Table 1: Percent, average attendance rate and average literacy instruction quality score and standard deviations by intervention and control and Indigenous status

\begin{tabular}{|l|l|c|c|c|}
\hline \multicolumn{2}{|l|}{} & $\mathrm{n}(\%)$ & $\begin{array}{c}\text { Attendance rate: } \\
\text { Mean (SD) }\end{array}$ & $\begin{array}{c}\text { Literacy instruction } \\
\text { quality: Mean (SD) }\end{array}$ \\
\hline Intervention & Indigenous & $67(56.8 \%)$ & $.80(.16)$ & $2.74(.77)$ \\
\cline { 2 - 5 } & Non-Indigenous & $51(43.2 \%)$ & $.93(.06)$ & $2.28(.50)$ \\
\cline { 2 - 5 } & Total & $118(100 \%)$ & $.86(.14)$ & $2.54(.70)$ \\
\hline \multirow{3}{*}{ Control } & Indigenous & $29(60.4 \%)$ & $.87(.09)$ & $2.23(.25)$ \\
\cline { 2 - 5 } & Non-Indigenous & $19(30.6 \%)$ & $.94(.06)$ & $2.41(.22)$ \\
\cline { 2 - 5 } & Total & $48(100 \%)$ & $.90(.09)$ & $2.30(.25)$ \\
\hline
\end{tabular}

While English as a second language (ESL) classifications were gathered for the students, permission to use this data in the analyses and reporting was not received 
from the NT Department of Education. From our classroom observations and conversations with teachers, however, we can say that many of the Indigenous students in our study spoke English as a second or third language.

\section{Analysis}

Students' ability estimates on the GRADE and PIPS-BLA pre- and post-tests were obtained using Rasch analysis and research questions were analysed using factorial ANCOVAs (see Appendix).

\section{Results}

\section{Equivalence of groups and attrition}

A between subjects two-way analysis of variance (ANOVA) was conducted to determine whether there were pretest ability score differences between control $(n=48)$ and intervention $(n=118)$ students, and between students who left the study $(n=57)$ and students who remained in the study $(n=166)$. The nineteen students who were excluded from the analyses due to contamination were not included in this analysis. There were no significant differences between treatment and control students' pretest scores, regardless of whether they remained in the study (see Table 2). Students who left the study, however, had significantly lower scores than students who remained on all outcomes except PIPS phonics. This suggests that the generalisability of our findings is somewhat limited to students who are more likely to attend regularly and remain enrolled in one school for a semester. There were no significant interactions between students who left and remained in the study between the intervention or control conditions.

Table 2: Pretest raw scores of students who remained in and left the study by intervention and control condition

\begin{tabular}{|c|c|c|c|c|c|c|c|}
\hline \multirow[b]{2}{*}{ Pretest variable } & \multicolumn{2}{|c|}{$\begin{array}{c}\text { Remained in study } \\
(\mathrm{n}=166)\end{array}$} & \multicolumn{2}{|c|}{$\begin{array}{l}\text { Left study } \\
\qquad(\mathrm{n}=57)\end{array}$} & \multicolumn{3}{|c|}{$\begin{array}{c}\text { ANOVA results } \\
F\end{array}$} \\
\hline & \begin{tabular}{|c|} 
Inter- \\
vention \\
$(\mathrm{n}=118)$
\end{tabular} & $\begin{array}{c}\text { Control } \\
(\mathrm{n}=48)\end{array}$ & $\begin{array}{c}\text { Inter- } \\
\text { vention } \\
(\mathrm{n}=38)\end{array}$ & $\begin{array}{l}\text { Control } \\
(\mathrm{n}=19)\end{array}$ & $\begin{array}{l}\text { In } \\
\text { study }\end{array}$ & \begin{tabular}{|c|} 
Inter- \\
vention \\
condition
\end{tabular} & $\begin{array}{l}\text { In study } \\
X \text { inter- } \\
\text { vention }\end{array}$ \\
\hline $\begin{array}{l}\text { GRADE K Phonological } \\
\text { awareness Mean (SD) }\end{array}$ & $\begin{array}{c}.19 \\
(1.26)\end{array}$ & $\begin{array}{c}.56 \\
(1.28)\end{array}$ & $\begin{array}{l}-.49 \\
(.97)\end{array}$ & $\begin{array}{l}-.74 \\
(.97)\end{array}$ & $24.92^{* * *}$ & 1.47 & .93 \\
\hline $\begin{array}{l}\text { GRADE K Word reading } \\
\text { Mean (SD) }\end{array}$ & $\begin{array}{c}-.43 \\
(1.55)\end{array}$ & $\begin{array}{c}-.68 \\
(1.62)\end{array}$ & $\begin{array}{l}-1.03 \\
(1.40)\end{array}$ & $\begin{array}{l}-1.80 \\
(1.35)\end{array}$ & $8.35^{* *}$ & 3.00 & .69 \\
\hline $\begin{array}{l}\text { GRADE K Early literacy } \\
\text { skills Mean (SD) }\end{array}$ & $\begin{array}{c}1.72 \\
(1.73)\end{array}$ & $\begin{array}{l}1.78 \\
(1.52)\end{array}$ & $\begin{array}{l}.37 \\
(1.59)\end{array}$ & $\begin{array}{c}.58 \\
(1.58)\end{array}$ & $15.62^{* * *}$ & .14 & .08 \\
\hline $\begin{array}{l}\text { GRADE K Phoneme } \\
\text { grapheme corres. Mean (SD) }\end{array}$ & $\begin{array}{c}.47 \\
(1.94)\end{array}$ & $\begin{array}{c}.60 \\
(1.74)\end{array}$ & $\begin{array}{l}-.66 \\
(1.70)\end{array}$ & $\begin{array}{l}-2.01 \\
(1.95)\end{array}$ & $26.40^{* * *}$ & 2.92 & 3.90 \\
\hline $\begin{array}{l}\text { PIPS-BLA Reading } \\
\text { Mean (SD) }\end{array}$ & $\begin{array}{c}-.01 \\
(1.58)\end{array}$ & $\begin{array}{c}-.13 \\
(1.76)\end{array}$ & $\begin{array}{l}-1.08 \\
(1.63)\end{array}$ & $\begin{array}{c}-1.40 \\
(1.38)\end{array}$ & $7.98^{* *}$ & .32 & .04 \\
\hline $\begin{array}{l}\text { PIPS-BLA Phonics } \\
\text { Mean (SD) }\end{array}$ & $\begin{array}{l}1.46 \\
(1.26)\end{array}$ & $\begin{array}{c}1.69 \\
(1.25)\end{array}$ & $\begin{array}{c}.70 \\
(1.52)\end{array}$ & $\begin{array}{l}1.33 \\
(.94)\end{array}$ & 2.91 & 1.56 & .39 \\
\hline
\end{tabular}

${ }^{*} \mathrm{p}<.05 ;{ }^{* *} \mathrm{p}<.01 ;{ }^{* * *} \mathrm{p}<.001$

\section{Does ABRACADABRA improve indigenous student literacy?}

A series of 2 (condition: intervention versus control) by 2 (Indigenous status: Indigenous versus non-Indigenous) between subjects ANCOVAs were run on the 
post-test data with pretest scores on the GRADE K and PIPS-BLA literacy subscales. Factorial ANCOVA tests revealed that, when controlling for pretest score, ABRACADABRA students had significantly greater post-test ability scores than control students on the GRADE K Phonological Awareness $\left(F_{1,165}=25.96, p<.001\right.$, $\eta^{2}=.14$ ) (see Table 3). There was a significant main effect of Indigenous status for all outcome measures except for the PIPS-BLA Phonics subscale (likely due to the small number of non-Indigenous students $[n=19]$ included in this analysis) (also see Table 3 ).

The interaction between Indigenous status and intervention was not significant for any of the analyses. The lack of a significant interaction suggests that ABRACADABRA is more effective than regular literacy instruction in improving both Indigenous and nonIndigenous students' phonological awareness. Table 3 displays the adjusted post-test means and standard errors for the GRADE and PIPS-BLA post-test ability scores and results of the $F$-tests.

Table 3: GRADE K and 1 and PIPS-BLA adjusted mean ability post-test scores, standard errors, and analysis of variance (ANCOVA) for intervention as a function of Indigenous status controlling for pretest ability

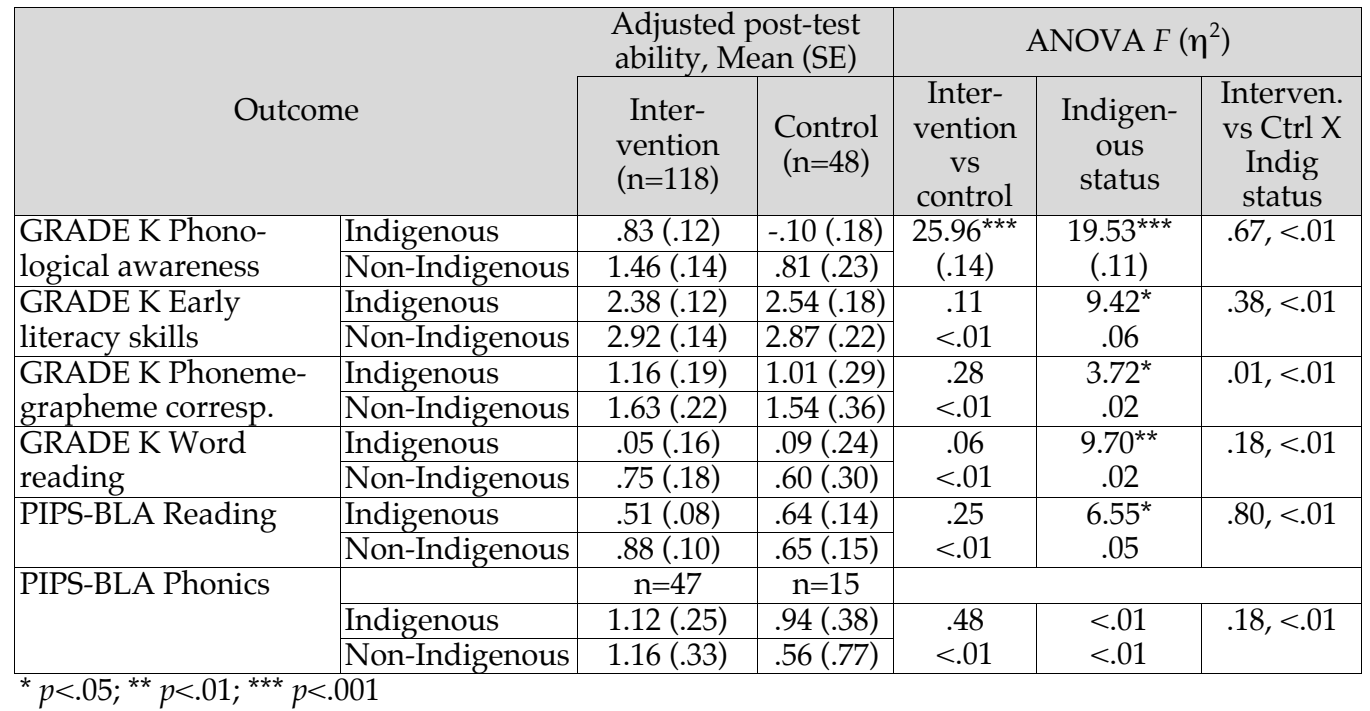

\section{Attendance and literacy instruction quality}

Student attendance was a significant predictor of GRADE K ELS and GRADE K word reading (see Table 4). Literacy instruction quality was a significant predictor of GRADE K phonological awareness. The significant findings align with other research that finds attendance (Ehrich, et al., 2010; Frontier, 2008; Thayer-Smith, 2007) and instruction/teacher quality (Heck, 2007; Stronge, Ward, Tucker \& Hindman, 2007) to be strong predictors of student achievement. Of interest is the finding that literacy instruction quality was significantly predictive only for phonological awareness. Teacher quality researchers (e.g., Darling-Hammond \& Young, 2002) have pointed out that the quality of instruction can be more important than both school and some student level variables in impacting student achievement. In our study, this seems true for delivering phonological awareness instruction, which literacy research indicates 
requires high quality direct instruction to improve student outcomes (Ball \& Blackmann, 1991; Davidson \& Jenkins, 1994; Ehri, 2009; Geva \& Siegel, 2000; NIHCD, 2000).

Table 4: ANOVA F and $\eta^{2}$ values for attendance rate and literacy instruction quality covariates for GRADE $\mathrm{K}$ and PIPS-BLA tests

\begin{tabular}{|c|c|c|c|}
\hline & \multicolumn{2}{|c|}{ ANOVA $F ; \eta^{2}$} \\
\hline & & $\begin{array}{l}\text { Attendance } \\
\text { rate }\end{array}$ & $\begin{array}{c}\text { Literacy instruction } \\
\text { quality }\end{array}$ \\
\hline \multirow{4}{*}{ GRADE K (n=161) } & Phonological awareness & $F=1.03 ; .01$ & $F=11.14^{\star \star} ; .07$ \\
\hline & Early literacy skills & $F=4.46^{*} ; .03$ & $F=2.82 ; .02$ \\
\hline & Phoneme-grapheme correspondence & $F=.43 ; .01$ & $F=3.82 ; .02$ \\
\hline & Word reading & $F=5.30^{\star} ; .03$ & $F=3.64 ; .02$ \\
\hline \multirow[t]{2}{*}{ PIPS-BLA Literacy } & PIPS-BLA Reading $(\mathrm{n}=144)$ & $F=1.8 ; .01$ & $F=.25 ; .01$ \\
\hline & PIPS-BLA Phonics $(\mathrm{n}=61)$ & $F=.11 ; .01$ & $F=2.96 ; .05$ \\
\hline
\end{tabular}

$R Q 2:$ Do the differences in research question 1 remain when students' post-test literacy scores are adjusted for by attendance and literacy instruction quality?

Attendance and literacy instruction quality were included as covariates in the ANCOVA models because they are highly variable in the NT and top educationalists' lists of reasons for poor Indigenous student literacy (see, for example, Ehrich, et al., 2010; Frigo, et al., 2004; Lyons, Cooksey, Panizzon, Parnell \& Pegg, 2006). By parsing out the variability associated with attendance and literacy instruction quality, we would have more power to detect differences between Indigenous and nonIndigenous, control and intervention students and their interactions. Non-significant intervention comparisons in the previous analyses would be more likely to be significant after adjusting for attendance and literacy instruction quality as known sources of variance. Yet, the adjustment could result in non-significant findings that had previously been significant. An example of this is; if the difference in literacy ability between Indigenous and non-Indigenous students was largely due to poor Indigenous student attendance, then adjusting for attendance would make Indigenous and non-Indigenous students' scores more similar.

The factorial ANCOVA tests revealed that when controlling for attendance and literacy instruction quality, the results remained the same. ABRACADABRA students had significantly greater post-test scores than control students only on the GRADE K Phonological Awareness $\left(F_{1,165}=30.90, p<.001, \eta^{2}=.17\right)$ (see Table 5).

Similar to the research question 1 findings, there was a significant main effect of Indigenous status for all outcome measures except for the PIPS-BLA Phonics subscale. The interaction between Indigenous status and intervention was not significant for any of the analyses. Of interest is that the $F$-values decreased (but remained significant) for the GRADE K ELS and word reading Indigenous status comparisons, when attendance and literacy instruction variables were included as covariates. This suggests that attendance and literacy instruction partially accounted for differences between Indigenous and non-Indigenous students' achievement in these two areas.

The quality of literacy instruction and student attendance did not account for differences in phonological awareness between students who did and did not receive ABRACADABRA instruction. This overall finding lends weight to the conclusion that 
ABRACADABRA is more effective than regular instruction for improving students' phonological awareness.

Table 5: ANOVA $F$ and $\eta^{2}$ values for research question 1 and 2 analyses

\begin{tabular}{|l|c|c|c|c|c|c|}
\hline \multirow{2}{*}{ Outcome } & \multicolumn{5}{|c|}{ ANOVA $F, \eta^{2}$} \\
\cline { 2 - 7 } & \multicolumn{2}{|c|}{ Intervention } & \multicolumn{2}{c|}{ Indigenous status } & \multicolumn{2}{c|}{ Interv. $x$ Indig. Status } \\
\cline { 2 - 7 } & RQ1 & RQ2 & RQ1 & RQ2 & RQ1 & RQ2 \\
\hline $\begin{array}{l}\text { GRADE K Phonological } \\
\text { awareness }\end{array}$ & $25.96, .14$ & $30.9, .18$ & $\begin{array}{c}19.53^{* * *} \\
.11\end{array}$ & $23.0^{* * *}, .13$ & $2.67,<.01$ & $2.52, .02$ \\
\hline $\begin{array}{l}\text { GRADE K Early literacy } \\
\text { skills }\end{array}$ & $.11,<.01$ & $.17,<.01$ & $9.42^{*}, .06$ & $3.98^{*}, .02$ & $.38,<.01$ & $.01,<.01$ \\
\hline $\begin{array}{l}\text { GRADE K Phoneme- } \\
\text { grapheme correspond. }\end{array}$ & $.28,<.01$ & $.71,<.01$ & $2.64^{*}, .02$ & $2.96^{*}, .02$ & $.01,<.01$ & $.66,<.01$ \\
\hline GRADE K Word reading & $.06,<.01$ & $.48,<.01$ & $9.70^{* *}, .02$ & $3.50^{*}, .03$ & $.18,<.01$ & $.12,<.01$ \\
\hline PIPS-BLA Reading & $.25,<.01$ & $.12,<.01$ & $3.55^{*}, .05$ & $3.97^{*}, .03$ & $.80,<.01$ & $1.91, .01$ \\
\hline PIPS-BLA Phonics & $.48,<.01$ & $1.36, .02$ & $.02,<.01$ & $.01,<.01$ & $.18,<.01$ & $.01,<.01$ \\
\hline
\end{tabular}
${ }^{*} p<.05 ;{ }^{* *} p<.01 ;{ }^{* * *} p<.001$

\section{Discussion}

The results of this study provide evidence that ABRACADABRA instruction improves both Indigenous and non-Indigenous students' phonological awareness as compared to regular literacy instruction in the NT. This finding was not altered when student attendance and literacy instruction quality, both of which are highly variable in the NT, were taken into account. The effect size for this comparison was large $\left(\eta^{2}=.14\right)$, which is all the more promising given the 'at risk' nature of much of our sample (students in remote communities with low attendance who receive less than ideal literacy instruction). The finding of the largest effects on phonological awareness is consistent with previous studies on ABRACADABRA in Canada (Comaskey et al., 2009; Savage et al., 2009) and may be somewhat explained by the training that emphasised ABRACADABRA's use for phonological awareness instruction.

That ABRACADABRA instruction improved phonological awareness is especially promising given 1) phonological awareness is an excellent predictor of outcomes at the end of primary education in the UK and Canada, even after SES and reading ability are considered (see, for example, Savage, Carless \& Ferrero, 2007), and 2) direct phonological awareness instruction is particularly important for improving the reading and writing skills of low-SES (NICHHD, 2000) and language minority students (Ehri, 2009; Geva \& Siegel, 2000), and that in the absence of effective supplementary tools, such instruction is highly dependent on prior teacher expertise. In the Handbook of Research on Literacy and Diversity, Ehri (2009) argues language minority children are more likely to begin school with very little foundational reading knowledge. "Whereas well-prepared children may scarcely be affected by instruction that slights foundational and word reading skills, ill-prepared children may find it devastating and may make little progress" (Ehri, 2009, p. 293).

The ABRACADABRA teachers appeared to be better prepared (through the teacher training) and equipped (with ABRACADABRA's 17 alphabetics activities) than control teachers to directly teach their students how to recognise and manipulate word sounds. In a survey designed to gather teacher perceptions, three of the six teachers commented they lacked training and experience to teach literacy, especially phonological awareness. This was echoed in focus groups conducted during the 
middle and end of the study. Teachers said ABRACADABRA helped them develop better lesson plans and identify strategies for direct instruction. One teacher said:

I feel I have gotten a better focus and overall understanding to my lessons since I started. Not being trained in early childhood I have very little knowledge about teaching phonemic awareness and ABRA provides me guidance in making sure I include these skills in my literacy lessons. There are lots of different phonic activities that one can be reminded to teach such as syllabication and word building.

Controlling for teacher quality means that the positive findings for phonological awareness cannot be attributed solely to the ABRACADABRA teachers' delivery of higher quality literacy lessons. It seems likely that ABRACADABRA's effectiveness in improving phonological awareness is also related to how it helped teachers deliver direct phonological awareness instruction and included enough variety and flexibility that most students received the recommended 20 hours of direct instruction not likely to have been provided in the control classrooms. It would appear that in our study the ABRACADABRA tool and associated training up-skilled teachers in phonological awareness instruction in a context where these skills are reportedly lacking.

In contrast to the strong effects of intervention condition on phonological awareness, there was less clear evidence that ABRACADABRA directly affected the outcomes for early reading skills, phoneme-grapheme knowledge, and phonics ability. The main effect of intervention did not approach significance for these analyses. There may be a number of reasons for this pattern. The first is that large effects for phonological awareness in the absence of major changes in word reading have been reported at immediate post-test in studies using ABRACADABRA in high risk, urban, low SES communities in Canada. Comaskey at al. (2009) found exactly this pattern among a sample where many families experience English as an additional language. While clearly quite distinct, it may be that there exists some commonality between the samples. Both studies contained many students with English as an additional language and who are also 'at risk' in terms of SES, and both shared a pattern of response to intervention in which phonological awareness but not reading ability showed the strongest growth. If so, it is worth bearing in mind that a follow up of the Comaskey and colleagues study (2009) by Di Stasio, Savage and Abrami (2010) indicates that one year after the ABRACADABRA intervention closed in Canada, significant effects of intervention were evident on reading comprehension, and medium sized effects of intervention were evident across a range of other literacy measures. It may be speculated that the effects of learning about the metacognitive process of phonological awareness take time to directly impact reading ability. Such a question can only be answered with certainty in the present context by running a follow up post-test some time after the intervention has formally closed.

\section{Limitations and future research}

There are several limitations that need to be considered when evaluating the study results. One limitation was the non-random allocation of classes to intervention and control conditions. In the interest of maintaining goodwill with the schools around our three year program of research, we elected to use an unequal sample size, quasiexperimental study. Further, practical constraints on conducting research in this context required a less rigorous design prior to running an RCT trial, rather than the use of a 'gold standard' RCT study in the first instance. Every effort was nevertheless undertaken to match groups such that control and intervention students did not differ 
significantly in age, Indigenous status or pretest ability scores, and to statistically control for extraneous factors (e.g., teaching quality, pretest reading ability). Nevertheless, well-executed RCT designs with fewer threats to internal validity may be best placed to detect effects of intervention on early reading. Importantly, preliminary evidence from an RCT study of ABRACADABRA in the Northern Territory (Wolgemuth et al., under review) has indicated effects of the ABRACADABRA intervention on a range of measures.

Our results may also be limited by the sample size. It is possible that the study was not adequately powered to detect differences in the interaction. This is especially true for the analysis of the PIPS-BLA phonics outcome. The unadjusted ability gain scores indicate it is possible that, had the study included more classrooms, we would have seen non-Indigenous students in the intervention outperform Indigenous students in the intervention, but not in the control group. Related, many of the students in our study spoke English as a second language. The size of our sample and failure to obtain departmental permission to use the ESL data meant we were unable to include this variable in the analysis, which may better account for the differences between Indigenous and non-Indigenous student literacy outcomes.

Another limitation is that teachers of varying experience and skills delivered the ABRACADABRA intervention. While this increased the ecological validity (or naturalness) of the study, it came at the expense of our ability to control the teaching environment. Even while the analyses controlled for overall teacher quality, our measurement of this complex variable was limited to a single instrument. There remains some question as to whether ABRACADABRA may be more effective in the hands of teachers determined to be highly skilled by multiple measures of instruction quality. Other ABRACADABRA studies suggest the quality of ABRACADABRA teaching and how well it is connected to the wider curriculum affects the power of the results. Savage and colleagues (2010) found that teacher variations in the use of ABRACADABRA affected student learning outcomes. Each of 3 teachers chose to use the program in qualitatively distinct ways that corresponded to the first three stages of Sandholtz, Ringstaff and Dwyer's (1997) technology integration model, namely: Entry, Adoption and Adaptation. Significant differences in growth in literacy between pre- and post-test were associated with technology integration style across all measures of literacy and related language skills. The largest and most widespread effects were evident for an Adaptation group that linked technology content to wider learning themes in the classroom. In terms of overall growth in standardised literacy scores across all six such measures used, Adaptation proved to be $60 \%$ more effective than other teaching methods.

The findings are also limited by the large number of students who left the study (24\% for the GRADE and 30\% for the PIPS). While attrition was not differential between the ABRACADABRA intervention and control groups, students who left the study had lower pretest scores for all outcomes than students who remained in the study, thus limiting the generalisability of our findings to students whose enrolment and attendance is relatively stable over a semester. The exclusion of the control class that used ABRACADABRA from the analysis is another limitation. Preliminary analyses showed that had this class been included as a control class, ABRACADABRA students would not have performed significantly better than control students on any of the outcome measures. It is impossible to tell whether this would have happened had the control class not used ABRACADABRA. 
Finally, the study findings are limited by our ability to determine the type and amount of exposure to ABRACADABRA that causes gains in student literacy. While ABRACADABRA is part of a larger software called the Learning Toolkit (LTK) which includes a program to monitor and record the types of activities students use, for how long and the number of correct responses, the LTK was not available until two weeks into the year two study and required teachers and students to log into a local installation of ABRACADABRA rather than access the free online version. While some teachers did have their students login after week two, they did not do so consistently and most teachers chose to use the free online version. Therefore the ABRACADABRA usage data was too inconsistent to be analysable. Attendance was used as a proxy variable for exposure to ABRACADABRA, but true exposure in terms of how much time students spent using different activities was not recorded.

These limitations have been addressed in a recently concluded randomised controlled trial in six NT schools, under which individual students were randomly assigned to ABRACADABRA and ABRACADABRA instruction was delivered by specially trained teachers. With over 350 students participating, the study has greater power to detect effects and exposure to ABRACADABRA and ESL status is being recorded and will be included in the analyses.

Subject to the results of the small-scale RCT, we further recommend ABRACADABRA be trialled in a larger study adequately powered to examine questions of its relative effectiveness in provincial, remote and very remote contexts and under varying literacy curriculum, for example.

\section{Summary and conclusion}

This study was driven by a pressing need to increase the literacy skills of struggling readers in regional and remote Australia, especially for Indigenous students during the critical early years of schooling. Results indicate that students who receive ABRACADABRA instruction outperform control students in phonological awareness. The finding is especially promising given direct phonological awareness instruction is known to be necessary for improving the reading and writing skills for low SES (NICHHD, 2000) and cultural minority students (Ehri, 2009; Geva \& Siegel, 2000). Overall, the results evidence that ABRACADABRA works in the Northern Territory to improve phonological awareness for students who attend, infrequently to consistently, provincial to very remote schools and receive varying qualities of literacy instruction. The fact that it is a free access, web-based resource produced significant effects on an important literacy skill after relatively brief training augers well for the future scalability and cost effectiveness of ABRACADABRA as one part of a program for effective early intervention in the NT. This approach may be particularly useful for supporting literacy in remote communities with reliable Internet access.

\section{Acknowledgments}

This research is supported by the Australian Research Council (ARC), Linkages Project (LP0990171) in partnership with the Telstra Foundation and the Northern Territory Department of Education and Training; and additionally by the Fred Hollows Foundation. Project website: http:/ / www.cdu.edu.au/sspr/abracadabra.html 


\section{References}

Abrami, P. C., Savage, R. S., Deleveaux, G., Wade, A., Meyer, E. \& Lebel, C. (2010). The Learning Toolkit: The design, development, testing and dissemination of evidence-based educational software. In P. Zemliansky \& D. M.Wilcox (Eds.), Design and implementation of educational games: Theoretical and practical perspectives (pp. 168-187). Hershey, PA: IGI Global.

Ah Kit, J. (2004). No School no Pool means Healthy Pools. Northern Territory Government media release, 19th April 2004. http: / / newsroom.nt.gov.au/2004/20040419_healthy_pools.shtml

Altman, D. G., Schulz, K. F., Moher, D., Egger, M., Davidoff, F., Elbourne, D. et al. (2001). The revised CONSORT statement for reporting randomized trials: Explanation and elaboration. Annals of Internal Medicine, 134, 663-694.

http: / / www.annals.org/content/134/8/663.abstract

Annadale, K., Bindon, R., Handley, K., Johnston, A., Lockett, L. \& Lynch, P. (2004). First Steps 2nd Edition Reading Resource Book.

http://www.ecurl.com.au/uk/resources/firststepsliteracy.asp

Australian Curriculum and Assessment Reporting Authority (ACARA) (2009). Shape of the Australian curriculum: English. Canberra, ACT: MCEECDYA.

http:/ / www.acara.edu.au/verve/_resources/Australian_Curriculum_-_English.pdf

Australian Curriculum and Assessment Reporting Authority (ACARA) (2010). 2009 NAPLAN National Report. Canberra, ACT: MCEECDYA. [verified 25 Jul 2011; 19.3 MB] http: / / www. nap.edu.au/_Documents/National\%20Report/NAPLAN_2009_National_Report.pdf

Ball, E. W. \& Blachman, B. A. (1991). Does phoneme awareness training in kindergarten make a difference in early word recognition and developmental spelling? Reading Research Quarterly, 26(1), 49-66. http:/ / dx.doi.org/10.1598/RRQ.26.1.3

Batten, M. \& Russell, J. (1995). Students at risk: A review of Australian literature 1980-1994. Camberwell, VIC: Australian Council for Educational Research.

Behrendt, L. \& McCausland, R. (2008). Welfare payments and school attendance: An analysis of experimental policy in Indigenous education. Univerity of Technology Sydney. http: / / www.aeufederal.org.au/Publications / 2008/LBehrendtpaper.pdf

Bodrova, E. \& Leong, D. J. (2007). Tools of the mind: The Vygotskian approach to early childhood education (2nd ed.). Upper Saddle River, NJ: Merrill/Prentice Hall.

Bourke, C., Rigby, K. \& Burden, J. (2000). Better practice in school attendance: Improving the school attendance of Indigenous students. Canberra, ACT: Department of Education, Training and Youth Affairs. http: / / www.dest.gov.au/NR/rdonlyres/BE155405-345F-4859-BCE6F0B86A248F37/2506/Attend_Synth.pdf

Brooks, G., Miles, J. N. V., Torgerson, C. J. \& Torgerson, D, J. (2006). Is an intervention using computer software effective in literacy learning? A randomised controlled trial. Educational Studies, 32(2), 133-143. http: / / dx.doi.org/10.1080/03055690500416116

Byrne, B. (1998). The foundation of literacy. Sussex: Psychology Press.

Cavanagh, R. F., Kent, D. B. \& Romanoski, J. T. (2005). An illustrative example of the benefits of using a Rasch analysis in an experimental design investigation. Paper presented at the Annual Meeting of the Australian Association for Research in Education: Sydney, NSW. http: / / www.aare.edu.au/05pap/ cav05081.pdf 
Centre for the Study of Learning and Performance (CSLP) (2009). The Learning Toolkit [Computer software]. Montreal, Canada: Centre for the Study of Learning and Performance, Concordia University. Version 1.0. http:/ / doe.concordia.ca/cslp/ICT-LTK.php

Comaskey, E. M., Savage, R. S. \& Abrami, P. (2009). A randomised efficacy study of Web-based synthetic and analytic programmes among disadvantaged urban Kindergarten children. Journal of Research in Reading, 32(1), 92-108. http: / / dx.doi.org/10.1111/j.14679817.2008.01383.x

Deault, L., Savage, R. \& Abrami, P. (2009). Inattention and response to the ABRACADABRA web-based literacy intervention. Journal of Research in Effective Intervention, 2(3), 250-286. http: / / dx.doi.org/10.1080/19345740902979371

Darling-Hammond, L. \& Young, P. (2002). Defining "highly qualified teachers": What does "scientifically based research" actually tell us? Educational Researcher, 31(9), 13-25. http: / / dx.doi.org/10.3102/0013189X031009013

Davidson, M. \& Jenkins, J. R. (1994). Effects of phonemic processes on word reading and spelling. Journal of Educational Research, 87(3), 148-157. http: / / www.jstor.org/ stable/ 27541912

Department of Education and Training (2011). Enrolment and attendance statistics. Darwin, NT: Northern Territory Government. http: / / www.det.nt.gov.au/students / at-school/ enrolmentattendance/ enrolment-attendance-statistics

Department of Employment, Education, and Training (DEET) (2008). Annual Report 2007-08. Darwin, NT: Northern Territory Government. http: / / www.det.nt.gov.au /_data/ assets / pdf_file/0018/4635/ AnnualReport.pdf

Department of Employment, Education, Training \& Youth Affairs (DEETYA) (1998a). The national report on schooling in Australia. Canberra, ACT: DEETYA. http: / / www.mceecdya.edu.au/mceecdya/anr_1998,12030.html

Department of Employment, Education, Training and Youth Affairs (DEETYA) (1998b). Literacy for all: The challenge for Australian schools: Commonwealth literacy policies for Australian schools. Canberra, ACT: DEETYA.

http: / / www.dest.gov.au/archive/schools/literacy\&numeracy/publications / lit4all.htm

Di Stasio, M., Savage, R. \& Abrami, P. (in press). A follow-up study of the ABRACADABRA web-based literacy intervention in Grade 1. Journal of Research in Reading. http: / / dx.doi.org/10.1111/j.1467-9817.2010.01469.x

Dunn, M. C., Kadane, J. B. \& Garrow, J. R. (2003). Comparing harm done by mobility and class absence: Missing students and missing data. Journal of Educational and Behavioral Statistics, 28(3), 269-288. http: / / dx.doi.org/10.3102/10769986028003269

Ehrich, J., Wolgemuth, J. R., Helmer, J., Oteng, G., Lea, T., Bartlett, C., Smith, H. \& Emmett, S. (2010). Attendance, performance and the acquisition of early literacy skills: A comparison of Indigenous and non-Indigenous school children. Australian Journal of Learning Difficulties, 15(2), 131-149. http:/ / dx.doi.org/10.1080/19404150903524580

Embretson, S. E. \& Reise, S. P. (2000). Item response theory for psychologists. Mahwah, NJ: Lawrence Erlbaum.

Fish, A., Li, X., McCarrick, K., Butler, S., Stanton, B., Brummit, G., et al. (2008). Early childhood computer experience and cognitive development among urban low-income preschoolers. Journal of Educational Computing Research, 38(1), 97-113. http: / / dx.doi.org/10.2190/ EC.38.1.e 
Frigo, T., Corrigan, M., Adams, I., Hughes, P., Stephens, M. \& Woods, D. (2004). Supporting English literacy and numeracy learning for Indigenous students in the early years. Indigenous Education, Paper 10. http:/ / research.acer.edu.au/indigenous_education/10

Frontier, A. C. (2008). What is the relationship between student engagement and student achievement? A quantitative analysis of middle school students' perceptions of their emotional, behavioral, and cognitive engagement as related to their performance on local and state measures of achievement. Unpublished Doctoral Dissertation. Cardinal Stritch University, Milwaukee, WI.

Garcia, M. R. \& Arias, F. V. (2000). A comparative study in motivation and learning through print-oriented and computer-oriented tests. Computer Assisted Language Learning, 13, 457-465. http: / / www.tandfonline.com / doi / abs / 10.1076/ 0958-8221\%28200012\%2913\%3A4-5\%3B1E\%3BFT457

Godfrey, J. R. \& Galloway, A. (2004). Assessing early literacy and numeracy skills among Indigenous children with the Performance Indicators in Primary Schools test. Issues in Educational Research, 14, 144-155. http:/ / www.iier.org.au/iier14/godfrey.html

Gray, B. \& Cowey, W. (2004). National Accelerated Literacy Program. http: / / www.nalp.cdu.edu.au/ whatisnalp.htm

Gray, J. \& Beresford, Q. (2008). A 'formidable challenge': Australia's quest for equity in Indigenous education. Australian Journal of Education, 52(2), 197-223. Retrieved from http: / / search.informit.com.au / documentSummary;dn=367622243947317;res=IELHSS

Gray, J. \& Hunter, J. (2000). Breaking the cultural cycle: Reframing pedagogy and literacy in a community context as intervention measures for Aboriginal alienation. Paper presented at the Annual Meeting of the American Education Research Association, New Orleans, LA, 2428 April) http: / / www.eric.ed.gov:80 / ERICWebPortal/ contentdelivery/servlet/ERIC Servlet?accno=ED441345

Gray, J. \& Partington, G. (2003). Attendance and non-attendance at school. In Q. Beresford \& G. Partington (Eds.), Reform and resistance in Aboriginal education: The Australian experience (pp. 133-163). Crawley, WA: University of Western Australia Press.

Heck, R. H. (2007). Examining the relationship between teacher quality as an organizational property of schools and students' achievement and growth rates. Educational Administration Quarterly, 43(4), 399-432. http:/ / dx.doi.org/10.1177/0013161X07306452

Helmer, J., Bartlett, C., Wolgemuth, J. R., Lea, T. \& Emmett, S. (2011). Coaching (and) commitment: Linking ongoing professional development, quality teaching and student outcomes. Professional Development in Education, 37(2), 197-211. http: / / dx.doi.org/ 10.1080/ 19415257.2010.533581

Helmer, J., Wolgemuth, J., Ehrich, J., Bartlett, C. \& Lea, T. (under review). Navigating the systemic hurdles in remote Australia: Conducting rigorous early childhood literacy research. Submitted to Issues in Educational Research, March 2011.

Hipps, G., Abrami, P. C. \& Savage, R. (2005). ABRACADARA: The research, design and development of web-based early literacy software. In S. Pierre (Ed.), Développement, intégration et évaluation des technologies de formation et d'apprentissage (DIVA). Innovations et tendances en technologies de formation et d'apprentissage (pp. 89-112). Montreal, QC: Presses Internationales Polytechnique.

Hitchcock, C. L. \& Noonan, M. J. (2000). Computer-assisted instruction of early academic skills. Topics in Early Childhood Special Education, 20(3), 145-158.

http: / / dx.doi.org/ 10.1177/027112140002000303 
Hutinger, P. L., Bell, C., Daytner, G. \& Johanson, J. (2006). Establishing and maintaining an early childhood emergent literacy curriculum. Journal of Special Education Technology, 21(4), 39-54. http: / / www.tamcec.org/jset-index/ establishing-and-maintaining-an-early-childhoodemergent-literacy-technology-curriculum/

Leigh, A. \& Gong, X. (2008). Estimating cognitive gaps between Indigenous and non-Indigenous Australians. Centre for Economic Policy research discussion paper. Canberra: Australian National University. http: / / ideas.repec.org/p/auu/dpaper/578.html

LeLoup, J. W. \& Ponterio, R. (December 2003). Second language acquisition and technology: A review of the research. [verified $25 \mathrm{Jul} 2011 ; 1.79 \mathrm{MB}$ ] http: / / www.cal.org/resources / digest/digest_pdfs/0311leloup.pdf

Louden, W. \& Rohl, M. (2003). Classroom literacy observation survey. In W. Louden, M. Rohl, C. Barrat-Pugh, C. Brown, T. Cairney, J. Elderfield, H. House, M. Meiers, J. Rivalland \& K. J. Rowe (Eds) (2005), In teachers' hands: Effective literacy teaching practices in the early years of schooling. Canberra, ACT: Australian Government Department of Education, Science and Training. http: / / www.dest.gov.au/NR/rdonlyres/2CE61B9C-C20B-4529-964B5953311E5738/10110/In_Teachers_Hands_FINAL_for_web.pdf

Louden, W., Rohl, M., Barrat-Pugh, C., Brown, C., Cairney, T., Elderfield, J., House, H., Meiers, M., Rivalland, J. \& Rowe, K. J. (Eds) (2005). In teachers' hands: Effective literacy teaching practices in the early years of schooling. Canberra, ACT: Australian Government Department of Education, Science and Training. http: / / www.dest.gov.au/NR/rdonlyres / 2CE61B9C-C20B4529-964B-5953311E5738/10110/In_Teachers_Hands_FINAL_for_web.pdf

Lyons, T., Cooksey, R., Panizzon, D., Parnell, A. \& Pegg, J. (2006). SiMERR National Survey. National Centre of Science, ICT \& Mathematics Education for Rural \& Regional Australia. New South Wales: University of New England. http: / / www.une.edu.au/simerr/pages/projects / 1nationalsurvey /index.html

Magnan, A. \& Ecalle, J. (2006). Audio-visual training in children with reading disabilities. Computers \& Education, 46(4), 407-425. http:/ / dx.doi.org/10.1016/j.compedu.2004.08.008

Masters, G. N. \& Forster, M. (1997). Mapping literacy achievement: Results of the 1996 National Schools English Literacy Survey. Canberra, ACT: Department of Education Employment, Training, and Youth Affairs. http:/ / www.dest.gov.au/mla/ contents.htm

McGarrigle, J. \& Nelson, A. (2006). Evaluating a school skills programme for Australian Indigenous children: A pilot study. Occupational Therapy International, 13(1), 1-20. http: / / dx.doi.org/10.1002/ oti.10

Mellor, S. \& Corrigan, M. (2004). The case for change. A review of contemporary research on Indigenous education outcomes. Australian Education Review, Australian Council for Educational Research. Camberwell, Victoria: ACER Press. http:/ / www.acer.edu.au/documents/AER_47-TheCaseforChange.pdf

Merrell, C. \& Tymms, P. (2007). What children know and what they can do when they start school and how this varies between countries. Journal of Early Childhood Research, 5, 115-134. http: / / dx.doi.org/10.1177/1476718X07076679

Moher, D., Schulz, K. F. \& Altman, D. G. (2001). The CONSORT statement: Revised recommendations for improving the quality of reports of parallel-group randomised trials. Lancet, 357, 1191-1194. http:/ / dx.doi.org/10.1016/S0140-6736(00)04337-3

Moore, D. S. (1995). The basic practice of statistics. NY: Freeman and Co. 
Morgan, G. A., Gliner, J. A. \& Harmon, R. J. (2006). Understanding and evaluating research in applied and clinical settings. Mahwah, NJ: Lawrence Erlbaum.

National Institute of Child Health and Human Development (NIHCD) (2000). Report of the National Reading Panel. Teaching Children to Read: An Evidence-Based Assessment of the Scientific Research Literature on Reading and its Implications for Reading Instruction, Report of the Subgroups. Washington, DC: U.S. Government Printing Office. http: / / www.nichd.nih.gov/ publications/nrp/upload/ report.pdf

Northern Territory Government Department of Education \& Training (2009). Compulsory teaching in English for the first four hours of each school day. http: / / www.det.nt.gov.au/aboutus / policies / documents / schools / compulsory-teaching-in-english-for-the-first-four-hours-ofeach-school-day

Northern Territory Government Department of Education \& Training (2009). Annual Report, 2008-2009. Darwin, NT: Northern Territory Government. http: / / www.det.nt.gov.au/_data/assets / pdf_file/0017/8252/FullVersion.pdf

Palincsar, A. S. (2003). Advancing a theoretical model of learning and instruction. In B. J. Zimmerman (Ed.). Educational psychology: A century of contributions (pp. 459-475). Mahwah, NJ: Erlbaum.

Phillips, B., Clancy-Menchetti, J. \& Lonigan, C. (2008). Successful phonological awareness instruction with preschool children: Lessons from the classroom. Topics in Early Childhood Special Education, 28(1), 3-17. http:/ / dx.doi.org/10.1177 / 0271121407313813

Sanders, W. L. \& Rivers, J. C. (1996). Cumulative and residual effects of teachers on future student academic achievement. Knoxville, TN: University of Tennessee Value-Added Research and Assessment Center. [not found 28 Jul 2011] http:/ / www.mccsc.edu/ curriculum/cum ulative $\% 20$ and $\% 20$ residual $\% 20$ effects $\% 20$ of $\% 20$ teachers.pdf

Savage, R. S., Erten, O., Abrami, P., Hipps, G., Comaskey, E. \& van Lierop, D. (2010). ABRACADABRA in the hands of teachers: The effectiveness of a web-based literacy intervention in grade 1 language arts programs. Computers $\mathcal{E}$ Education, 55(2), 911-922. http: / / dx.doi.org/10.1016/j.compedu.2010.04.002

Savage, R. S., Abrami, P., Piquette-Tomei, N., Wood, E. \& Delevaux, G. (2008). ABRACADABRA: A study in the development, implementation and effectiveness of a web-based literacy resource. A research progress report. Report submitted to the Canadian Council for Learning and the Canadian Language and Literacy Research Network. http: / /www.cclcca.ca/pdfs / OtherReports / Abrami-ABRA-ReportE.pdf

Savage, R., Abrami, P. C., Hipps, G. \& Wade, A. (2009). A randomized control trial study of the ABRACADABRA reading intervention program in grade 1. Journal of Educational Psychology, 101, 590-604. http: / / dx.doi.org/10.1037/ a0014700

Savage, R., Carless, S., \& Ferrero, V. (2007). Predicting curriculum and test performance at age 11 years from pupil background, baseline skills and phonological awareness at age 5 years. Journal of Child Psychology and Psychiatry, 48, 732-739. http:/ / dx.doi.org/10.1111/j.14697610.2007.01746.x

Steering Committee for the Review of Government Service Provision (SCRGSP) (2009). Overcoming Indigenous disadvantage: Key indicators 2009. Canberra: Productivity Commission. http: / / www.pc.gov.au/_data/assets / pdf_file/0003/90129/ key-indicators-2009.pdf

Stronge, J. H., Ward, T. J., Tucker, P. D. \& Hindman, J. L. (2007). What is the relationship between teacher quality and student achievement? An exploratory study. Journal of Personnel Evaluation in Education, 20, 165-184. http:/ / dx.doi.org/10.1007/ s11092-008-9053-z 
Thayer-Smith, R. A. (2007). Student attendance and its relationship to achievement and student engagement in primary classrooms. Unpublished doctoral dissertation. College of William and Mary, Williamsburg, VA.

Tymms, P. (2002). Baseline assessment, value added and the prediction of reading. Journal of Research in Reading, 22, 27-36. http:/ / dx.doi.org/10.1111/1467-9817.00066/

Williams, K. T. (2001). Group reading assessment and diagnostic evaluation: Technical manual. Shoreview, MN: Pearson AGS Globe.

Wise, S., da Silva, L., Webster, E. \& Sanson, A. (2005). The efficacy of early childhood interventions. Melbourne: Australian Institute of Family Studies.

http:/ / www.aifs.gov.au/institute/pubs/resreport14/aifsreport14.pdf

Wolgemuth, J. R., Helmer, J., Emmett, S., Bottrell, C., Lea, T., Bartlett, C., Harper, H., Abrami, P. \& Savage, R. (2009). ABRACADABRA! (ABRA) Early Childhood Literacy Project Annual Report No. 2: A quasi-experimental study of the ABRA literacy software in Northern Territory Indigenous classrooms. Charles Darwin University, Darwin, NT.

http:// www.cdu.edu.au/sspr/documents/ABRA_2009_Annual_Report.pdf

Wolgemuth, J. R., Savage, R., Helmer, J., Harper, H., Lea, T., Abrami, P., Chalkiti, K. \& Kirby, A. (under review). The impact of ABRACADABRA on Indigenous and non-Indigenous early literacy in Australia: A multisite randomized controlled trail. Manuscript submitted to Reading Research Quarterly, July 2011.

\section{Appendix: Analyses}

\section{Item analysis}

Rasch analyses were conducted on the GRADE $\mathrm{K}$ form $\mathrm{A}$ and $\mathrm{B}$ and the PIPS-BLA instruments to a) eliminate any misfitting and differentially functioning items, b) assess the Person Separation Index (internal consistency) and determine the fit of the items to the Rasch model, c) to assess whether the assessment was well-targeted for the sample, and d) calculate students' ability scores. The analysis was conducted on a combined pre- and post-test database to place both tests on the same scale in order to estimate differences with a higher level of certainty (Cavanagh, Kent \& Romanoski, 2005).

The Rasch logistic model for dichotomous items calculates the probability of success by a person $n$ on an item $i$ as a function of the ability of the person $\left(\theta_{n}\right)$ and the difficulty of the item $\left(\beta_{i}\right)$ (See Equation 1) (Embretson \& Reise, 2000).

$$
P\left\{X_{n i}=1 \mid \theta_{n}, \beta_{i}\right\}=\frac{e^{\left(\theta_{n}-\beta_{i}\right)}}{1-e^{\left(\theta_{n}-\beta_{i}\right)}}
$$

Since a person's ability and item difficulty are located on the same scale in Rasch modeling, the person's ability, $\theta_{n}$, is calculated as the point where a person has a .50 probability of getting an item of difficulty, $\theta_{i}$, correct and values typically range from -3 to 3 . Therefore Rasch analysis takes into account the difficulty of the individual test items, yielding a more accurate estimate of students' literacy abilities than their raw scores. 
Items that did not fit the Rasch model (e.g., students with higher abilities did not perform better on these items than students with lower abilities) were eliminated from the analyses based on the conservative criteria that their fit residuals were between +2.5 and -2.5 and the Bonferroni adjusted $p$-value was <.01. Four items were removed from the analysis of GRADE K A and five items were removed from GRADE $K \mathrm{~B}$. Six items were removed from the PIPS-BLA for the same reason. Items were also assessed for Differential Item Functioning (DIF) between Indigenous and non-Indigenous students. No items on the GRADE K or PIPS-BLA instruments displayed significant DIF (Bonferroni adjusted $p$-value <.01).

The Person Separation Index for the GRADE K A and B and the PIPS-BLA Literacy were all high, indicating a good fit of the data to the model $\left(r_{\text {beta }}=.94, .94\right.$, and .93, respectively). Consistent with the Separation Index, the mean Fit Residuals all indicated good fit for the items of each test (GRADE K A, M=-.30, SD=1.47; GRADE K $\mathrm{B}, \mathrm{M}=-.44, \mathrm{SD}=1.56$; PIPS-BLA Literacy, $\mathrm{M}=-.08, \mathrm{SD}=1.34)$. Separation indices for the GRADE K subscales were acceptable, ranging from .68 to .83 . The separation index for the PIPS-BLA reading subscale was high (.94), but the separation index for the phonics subscale was moderate (.54).

For all students taking the GRADE K A and B at pre- and post-test, item difficulties ranged from approximately to -3 to just over 2 while student abilities ranged from -4.5 to just over 5 . The average ability estimates for forms $A$ and $B$ were $0.86(S D=1.54)$ and $.96(\mathrm{SD}=1.56)$, indicating the tests were slightly easy for the students in the study (a well-targeted test would have an average ability estimate of zero) and were sufficiently similar that they could be analysed together.

For all students taking the PIPS-BLA Literacy at pre- and post-test, item difficulties ranged from approximately to -4.5 to just over 4 , while student abilities ranged from -4 to just over 4.5 . The average ability estimate was $0.40(\mathrm{SD}=1.32)$, indicating the test was well targeted for students in the study.

\section{Research questions}

Research question 1 was analysed using a factorial ANCOVA with condition (intervention and control) and Indigenous status (Indigenous and non-Indigenous) controlling for pretest ability score on the GRADE ability post-test scores and the PIPSBLA ability post-test scores. Research question 2 was analysed by adding attendance rate and literacy instruction quality as additional covariates in the analysis for research question 1. A Type I sum of squares analysis was conducted for both analyses in the following order: pretest ability covariate (attendance covariate, literacy instruction quality covariate - for research question 2), Indigenous status, intervention and the Indigenous status and intervention interaction. This analysis order was chosen so that the ABRACADABRA intervention versus control main effect comparison was not unnecessarily adjusted for by the intervention by Indigenous status interaction.

ANCOVA assumptions of normal distributions, linearity, and homogeneity of regression slopes were met for all analyses. In the cases where the homogeneity of variances assumption was violated (GRADE K phonological awareness, early literacy skills, and phoneme-grapheme correspondence), it was decided to proceed with the ANCOVAs as ANOVA is robust to small (ratio of 3 to 1) and moderate (ratio of 4 to 1) violations of variance homogeneity (Moore, 1995). 
Authors: Dr Jennifer Wolgemuth, Assistant Professor, Colorado State University, School of Education, Fort Collins, CO 80523, USA

Email: Jennifer.Wolgemuth@colostate.edu

Web: http: / / www.cdu.edu.au/sspr/profiles / wolgemuth-j2.htm

Dr Robert Savage, Associate Professor, McGill University, Faculty of Education, Education Building B183, 3700 McTavish Street Montreal, Quebec, CANADA H3A 1Y2. Email: Robert.savage@Mcgill.edu.ca

Web: http: / / www.mcgill.ca/literacy-advocacy/researchteam/robertsavage /

Dr Janet Helmer, Research Fellow, Menzies School for Health Research, Darwin NT 0909, Australia. Email: Janet.Helmer@cdu.edu.au

Web: http: / / www.cdu.edu.au/thenortherninstitute/jhelmer.html

Dr Christine Bottrell, Research Fellow, Charles Darwin University, Darwin NT 0909, Australia. Email: Christine.Bottrell@cdu.edu.au

Web: http:/ / www.cdu.edu.au/thenortherninstitute/cbottrell.html

Associate Professor Tess Lea, QE II Fellow, University of Sydney, Sydney NSW 2006,

Australia. Email: Tess.Lea@sydney.edu.au

Web: http: / / www.cdu.edu.au/thenortherninstitute/tlea.html

Dr Helen Harper, Research Fellow, Menzies School for Health Research, Darwin NT 0909, Australia. Email: Helen.Harper@cdu.edu.au

Web: http:/ / www.cdu.edu.au/thenortherninstitute/hharper.html

Dr Kalotina Halkitis, RARI Implementation Officer, Northern Territory Department of Children and Families, Casuarina, NT 0810, Australia

Email: Kalotina.Halkitis@nt.gov.au

Web: http:/ / www.cdu.edu.au/thenortherninstitute/khalkitis.html

Professor Phil Abrami, Centre for the Study of Learning \& Performance LB-589-2,

Concordia University, 1455 DeMaisonneuve Blvd. West Montreal, Quebec, Canada

H3G 1M8. Email: abrami@education.concordia.ca

Web: http:/ / doe.concordia.ca/cslp/

Please cite as: Wolgemuth, J., Savage, R., Helmer, J., Bottrell, C., Lea, T., Harper, H., Halkitis, K. \& Abrami, P. (2011). Using computer-based instruction to improve indigenous early literacy in Northern Australia: A quasi-experimental study.

Australasian Journal of Educational Technology, 27(4), 727-750.

http:/ / www.ascilite.org.au/ajet/ajet27/ wolgemuth.html 